\title{
DESIGNING EXPERIENTIAL TRAINING IN LEAN PRODUCT DEVELOPMENT: A COLLABORATION BETWEEN INDUSTRY \& ACADEMIA
}

\author{
Eric BLANCO ${ }^{1}$, Stephanie BERARD ${ }^{2}$, Sylvie BLANCO ${ }^{2}$, Pierre CHEVRIER ${ }^{1}$, Emmanuelle \\ HEIDSIECK ${ }^{2}$, John KENWRIGHT ${ }^{4}$, Virginie VERGES ${ }^{3}$ \\ ${ }^{1}$ Univ. Grenoble Alpes, CNRS, Grenoble INP, G-SCOP 38000 Grenoble, France \\ ${ }^{2}$ Grenoble Ecole de Management \\ ${ }^{3} \mathrm{ST}$ Microelectronics SA \\ ${ }^{4}$ Univ. Grenoble Alpes, Grenoble INP, 38000 Grenoble, France
}

\begin{abstract}
This paper presents how collaboration between academics and industry initiated in the context of a local innovation consortium led to the design of a training programme in lean development.

The approach inspired from design thinking principles was developed by an interdisciplinary team of researchers in $R \& D$ efficiency and agile project management, pedagogical advisors, specialists in serious game design and project management from academia, lean experts and engineers from the company. Intense collaboration, experience-based inspiration, rapid prototyping including engineers from the company, observers from university, quick learning loops and feedback, contributed to the development of this training programme. This collaboration favoured discussion in terms of expectations from the company and setting up the foundation of the training programme including the constraints of deploying the course for up to 2000+ targeted people worldwide. Experiential learning through serious games and case studies is the pedagogical foundation of the teaching material.

The paper discusses the training design process, hypothesis and objectives. All stakeholders learnt from this design thinking approach, leading to innovative training co-creation and demonstrating the richness of interdisciplinary teamwork and relevance of a user-centred approach for lifelong learning training design.
\end{abstract}

Keywords: Lean development, $R \& D$, lifelong learning, serious games, experiential learning

\section{INTRODUCTION}

Performance and efficiency in R\&D processes is a critical point for industry. Operational excellence in design and development is required to overcome the business challenges that companies face. It is the case in the semiconductor industry where products have to be developed quicker whilst maintaining a high level of quality. Study of design practices in aerospace have illustrated that only about $10 \%$ of design activity is spent on creating value [1]. If this number appears alarming, many engineers participating in design activity agree that practices could be improved to address issues in efficiency and performance. Lean product development is viewed as a global approach that offers a framework to address design performance [2]-[4]. This approach was chosen by a large semiconductor company to achieve its full agile transformation, modifying both practices and mindset of global R\&D teams. A large training programme was designed with the contribution of academic partners to overcome onsite reluctance to participate in traditional courses. A process inspired by Design Thinking Principles [5] was proposed to cope with the challenge through an interdisciplinary team involving multiple stakeholders (including targeted trainees). The next section will present context and initial pedagogical choices and the hypothesis of the training programme. Section 3 will describe our process focusing on some key elements and giving feedback from the first training sessions. Finally, section 4 discusses the lessons learnt from this design process and opening to perspectives for use of material in initial training. 


\section{PROJECT CONTEXT AND HYPOTHESIS}

\subsection{Company challenge}

The challenge for the company is substantial since it concerns more than 2000 engineers spanning 6 countries. It concerns a large strategic programme to increase client centric $R \& D$ focus and improve $\mathrm{R} \& \mathrm{D}$ efficiency. The objective is to transform practices and introduce lean development approach as a new standard of working. A similar transformation had previously been carried out in the company in the deployment of lean manufacturing supported by a large training programme. On the strength of this successful experience, the managers of R\&D and HR decided to launch a similar programme in R\&D. Partners are linked in a consortium, namely the Institute for Research and Technology in Nanoelec (IRT Nanoelec) within which a track is dedicated to training programmes. The objectives of this IRT Nanoelec pole is to support research-industry collaborations so as to foster technology transfer and new tech-based venture creation. Thus, the company requested academic input in developing a customised programme to implement a lean development mindset on a global scale.

The initial brief had been defined as a set of tools that the company wanted to include as a common standard inside the R\&D teams. The training programme was to be aligned with company's lean manufacturing system. Of course, the sheer volume of training that it represented, as well as logistic and organisational aspects were constraints to be taken into account. Training had to fit into a maximum 3day programme and the schedule was also short since the first training needed to be launched in 2019 . Nevertheless, the main objective was to support the transformation of the whole organisation.

\subsection{Experiential learning as a foundation.}

Since the objective is to transform $R \& D$ practices through the global company, learner experience needed to be motivating and engaging for a future implementation of lean development. Experiential learning [6] as defined by Kolb [6] grounded in theoretical background from Dewey, Schön and Piaget [7], was chosen as a pedagogical approach. In engineering higher education, experiential learning is often used in project-based learning, problem-based learning or case studies [8]. Serious games appear to generate engaging situations for trainees. Lean development deals with continuous improvement so learning from errors seems to be useful and failing in low stakes environments for professionals in a game was a good starting point. Games include emotion, cognition and social interaction in the learning experience, which are important in changing collective and individual behaviours. Thus, gaming appeared to be a good lever to support our pedagogical objectives.

Serious games are simulations of authentic situations where learners share a common experience. Games and simulations are used as a safe experience where risk-taking and partial failure are encouraged. Reflection and observation on failure is used to encourage abstraction engaging trainees in the Kolb's experiential learning circle [6]. In lifelong learning professionals already have individual experience and games appear to operate as catalysers to densify in a short-time phenomenon appearing in authentic situations. From the Concrete Experience (CE) in the game, individual and collective Reflective Observation (RO) is encouraged and Abstraction Conceptualisation (AC) can take place with the teachers. Renewing the game with new hypothesis can lead to a successful and new real experience such as in Active Experimentation (AE) where some aspects of previous difficulties can be mastered. Thus, all the steps of Kolb's learning cycle can be addressed. Different Games mechanics [9] could be used in order to create similarity with professional experiences. Game serve as shared real experience that simulates authentic situations that professionals often encounter in their activities.

\section{MAIN STEPS OF THE DESIGN PROCESS}

\subsection{Design thinking approach}

The design thinking approach was chosen to design the programme. User-centred design, interdisciplinary team and rapid prototyping were the main principles adopted by the team. The team was interdisciplinary integrating multiple stakeholders of the training in the design process: HR personnel, engineers, managers and lean manufacturing experts from company sharing experience, requirement expectations and concerns. The design team also included consultants, pedagogical experts, a serious game designer and professors from management and engineering schools with different backgrounds in project management, R\&D efficiency and innovation management. Thanks to company commitment, user integration could be implemented as a participatory design. Company stakeholders 
were included in different workshops for inspiration and data collection about context, expectation of trainees and later for rapid feedback from prototyping. The process was initially organised in three phases: Inspiration, Ideation and Implementation with different workshops. The company put an attaché on full-time disposal for the project who was given workspace on site with the academic partners to facilitate the coordination of the project and its communication.

\subsection{Inspiration: The Initial workshops}

Before starting the design of the training, two different workshops were organised. The first workshop was mainly an introduction to lean development and the tools that the firm wanted to deploy as standards. The second workshop was focused on the identification of R\&D engineers' needs, fears and constraints. 25 people participated in this second workshop. During this working day, operational R\&D engineers expressed the following:

- $\quad$ Top key focus and help needed

- "Balloons", items contributing to positive dynamic during new product development project

- "Anchors", items slowing down new product development process

- Nightmare/unbearable training approaches versus successful ones

During these two days, engineers' daily work feelings were openly discussed. Successful R\&D project dynamics, conditions and the influence of managerial behaviour were also highlighted. Hereafter are quoted some typical verbatim expressed during these fruitful exchanges:

- "Due to short delay imposed by the management, fast start of the R\&D project causes some technical debt. Afterwards, this technical debt slows down the development process and leads to solutions which fall short of full satisfaction"

- "There is a lack of communication, a directive style of management, a lack of empowerment and trust"

- "Our customers are not challenged, their needs not analysed enough with functional view"

- "We accumulate projects without clarifying and sharing priorities. This leads to collapsed situations"

Integration of future trainees during the inspiration phase was fruitful for trainers and helpful in continuously adjusting the training programme architecture and its pedagogical choices. Collected data from workshops were used by training designers all along the process to tweak and guide in engineering the course content.

\subsection{Ideation: Training programme architecture}

Following these inspiration workshops key decisions were agreed upon:

- Interactive training is preferred, and gamification of training activities will be encouraged

- First training objective is to develop lean development culture

- Lean development culture is based on mindsets \& behaviours and is not just a tool box

- The Taxi Drone environment was a common theme of the training

The architecture of the training programme was decided on (fig1). The programme includes 2 days of face to face learning using experiential learning and one accompanying day later with implementation progress monitoring and return and sharing on experience as a whole.

On the basis of brainstorming activities, academic experts proposed to focus the first training day on the concept of Value: Perceived Customer Value on one side, Added Value in Development project on the other. The second training day would be centred on Product/Project Development Flow: influence of multitasking, individual and collective time management, batch size, fast feedback. Serious games and study cases were built following this global training architecture.

The last half-day is used to run a workshop articulated on the participant's own problems. A community of practice with a collaborative platform and in vivo sharing sessions supports the transformation. Two serious games, a case study and problem-based learning session had to be developed to introduce the main concepts chosen as the heart of the programme.

Thus the experiential learning cycle of Kolb [6] is respected on two levels: within a half-day session with the first round of the game (EC), debrief and exchange (RO) theoretical input (AC) and the second round of the game (AE) that allows players to experience improvement. On a macro level the last day allows to share own personal experience (EC-RO) and to plan operational change in context using new knowledge acquired during training (AC-AE). 

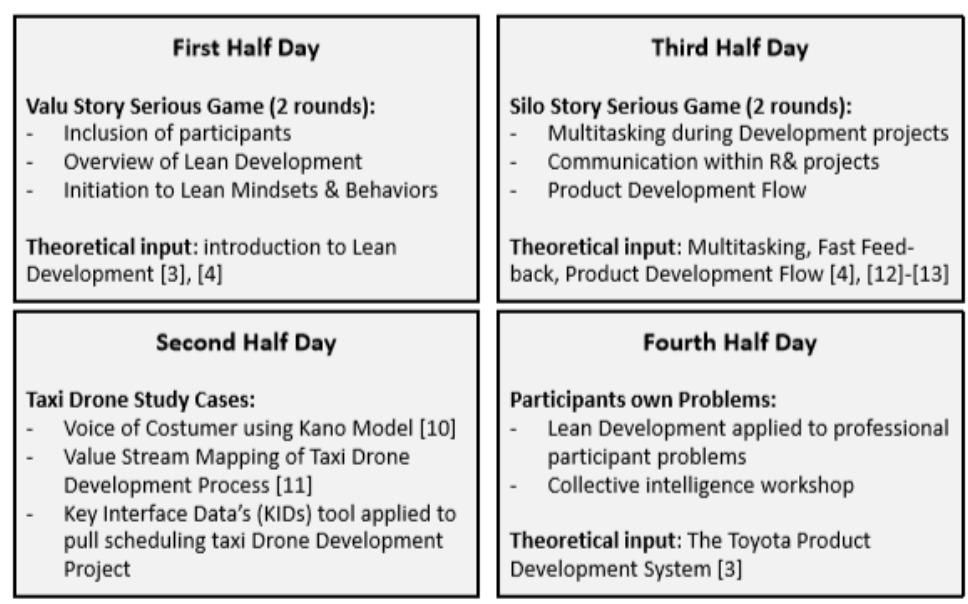

Figure 1. Typical 2 days face to face Training Session [3], [4][10]-[13]

\subsection{Implementation: detailed design and prototype}

A prototype of the training material was designed by academic partners. Fast prototyping approach was used to improve the different modules of the training. A single module was first tested with industrial engineers. During this test phase, a set of observers analysed the training process. Pedagogical specialists, lean development experts and industry managers were included in the observers' team. Structured surveys were filed. Return on Experience (ROE) from trainees and trainers was shared after each test of a single module. Continuous Improvement (CI) actions were identified between partners and setup for the next test session (figure 2).

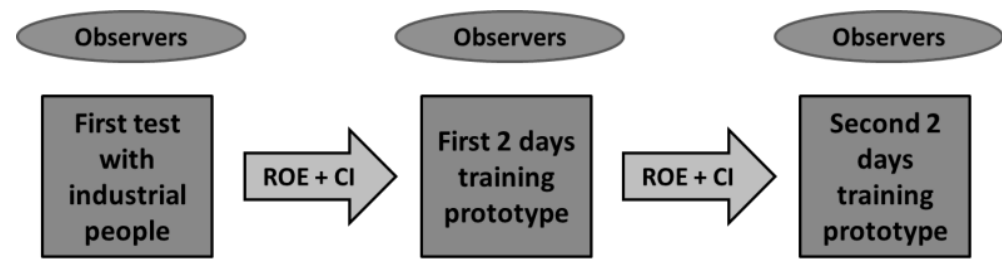

Figure 2. 3 loop improvement schemes applied on each game or study case

Following the single module test, two prototypes of the complete 2-days training were organised with a 3 -week interval period allowing the training designers to take into account suggested improvements (figure 2). Observations were made, and a continuous improvement loop was systematically set up.

Table 1. Global evaluation of game activity

\begin{tabular}{|c|c|c|c|c|c|c|}
\hline $\begin{array}{c}\text { Global evaluation } \\
\text { of game activity }\end{array}$ & Excellent & Good & Sufficient & $\begin{array}{c}\text { Not } \\
\text { Sufficient }\end{array}$ & $\begin{array}{c}\text { Not } \\
\text { Sufficient } \\
\text { at all }\end{array}$ & Bad \\
\hline First test & 2 & 6 & 3 & & 0 & 0 \\
\hline First prototype & 3 & 7 & 0 & 0 & 0 & 0 \\
\hline Second prototype & 11 & 0 & 0 & 0 & 0 & 0 \\
\hline
\end{tabular}

\subsection{Example: application to Silo Story Serious Game}

The Silo Story Serious game was built in order to simulate multitasking impact on design office activities, its objectives being to break silos, improve communication, manage multitasking and visualise queues. During this Silo Story game, players have to solve simple arithmetic equations (taxi drone design rules) requiring concentration. Frequent interruptions occur, because of production support needs or customer requests including the notion of chance and crisis management in the game.

As described previously, 3 improvement loops were set up with industrial participants. Each time, the game's activity was composed of 2 rounds. At the end of the simulation, a questionnaire was filled out by the participants. The last item of the questionnaire was about the global evaluation of game activity. Table 1 summarises the general feedback from the Silo Story game simulation. Table 1 clearly shows the effectiveness of continuous improvement. 
From a qualitative point of view, figure 3 describes typical improvements, which were set up between two loops:

- After the $1^{\text {st }}$ simulation: Silo Story game was perceived as being funny and the commitment of participants was excellent. But the pedagogical objectives were not fully met. Indeed, communication between participants was too easy and failures thus avoided. As a consequence, silos were not well simulated. In order to better simulate hard communication, emails were introduced into the game via obligatory post-its.

- After the $2^{\text {nd }}$ simulation: difficulties relating to communication were well simulated. However, interruptions due to production or customer support, illness of designers, celebration of events ... did not really disturb participant concentration on design tasks. In order to better create the switching between 2 activities, Lego blocks were added to the game. During each interruption, participants had to create added-value by building a nice control tower dedicated to supervising the taxi drone traffic.

- The $3^{\text {rd }}$ simulation demonstrated a full commitment of all participants and realistic behaviours of design office actors.

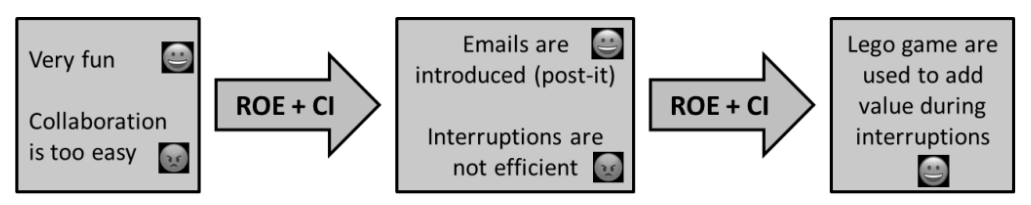

Figure 3. 3 loop improvement - Application to Silo Story Game

This iteration process was setup for each game and each case study. In addition, the iteration process was also requested in order to align the objectives between academic and industrial partners.

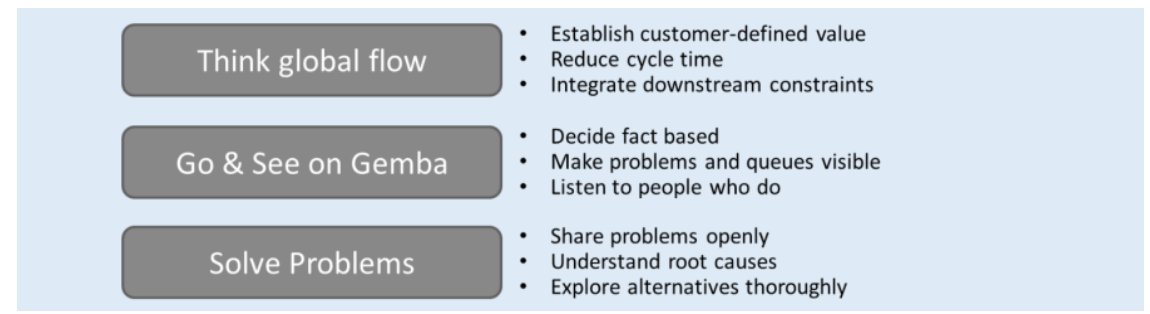

Figure 4. Extract of Lean Mindsets \& Behaviours as defined after 4 'Sanity Check' loops

\subsection{Alignment of Lean Development Mindsets and Behaviours}

During a cultural change, leadership behaviours are fundamental. This is why, alignment on lean development mindsets was mandatory. In such a way, so called "Lean Mindsets \& Behaviours" were accurately defined through several iterations between academic and industrial project partners. The final proposition based on 6 key Mindsets \& Behaviours (figure 4) was agreed during a 'Sanity Check' meeting. A Sanity Check meeting was essential to confirm that lean development was understood in the same way by all training project partners.

\section{DISCUSSION AND PERSPECTIVES}

Looking back to the training design process and taking into account the success of the first training sessions (excellent level of trainees' feedback higher than 75\%), 4 main strengths can be highlighted:

- Design team was interdisciplinary: mixing serious game, lean development, pedagogy and project management experts was a unique opportunity to create serious games and case studies allowing trainees to feel authentic situations and similarities while sharing a real experience (immersive strength of experiential learning requires access to real-life situations).

- Initial demand of the company was reformulated: following the 2 initial inspiration and ideation days, training was more focused on lean mindset and behaviour than just lean tools.

- User-centred training design: owing to company support, future trainees were continuously involved in the training design offering unique opportunity to gain access to real experience. 
- Prototyping: games and case study were prototyped and continuously improved owing to 3 loops involving company engineers; each prototype test was supervised by pedagogical experts and company managers and their feedback was precious.

All stakeholders learnt from this design thinking approach, leading to innovative training co-creation. Roles, from either academics or industry people, emerged through carrying out the project, demonstrating the richness of interdisciplinary team and relevance of user-centred approach for lifelong learning training design.

One identified weakness of our training design is that traceability of ideation process is not reliable. A lot of interaction loops occurred at different moments of the design. This feedback was obtained through phone calls, short meetings or even email exchanges. They were necessary to check that the designed training course catered directly to the initial request, but they were not well structured.

Training material will be used for engineers and master students during their academic training. The lack of professional experience of students requires the redesigning of some training modules or using them differently. As an example, the Silo Story game will support portfolio management strategies looking for best scenarios concerning the number of projects to be developed by the team in parallel. Students groups will be able to play different scenarios in Active Experimentation (AE).

\section{ACKNOWLEDGEMENTS}

This work has been supported by the French State in the frame of the IRT Nanoelec project, ANR-10AIRT-05

\section{REFERENCES}

[1] Oehmen J. and Rebentisch E. "Waste in Lean Product Development," LAI Pap. Ser., no. July, pp. $1-35,2010$.

[2] Khan M. S. et al., "Towards lean product and process development," Int. J. Comput. Integr. Manuf., vol. 26, no. 12, pp. 1105-1116, Dec. 2013.

[3] Morgan J.M. and Liker J.K. The Toyota Product Developement System: Integrating People Process and Technology. New York: Productivity press, 2006.

[4] Reinertsen D.G. The principles of Product Development Flow. Second Generation Lean Product Development. Celeritas Publishing, 2009.

[5] Brown T. "Design Thinking," Harv. Bus. Rev., no. June, 2008.

[6] Kolb D.A. Experiential Learning: Experience as the Source of Learning and Development, 2nd editio. pearson education, 2014.

[7] Balleux A. "Évolution De La Notion D’Apprentissage Expérientiel En Éducation Des Adultes: Vingt-Cinq Ans De Recherche," Revue des sciences de l'éducation, vol. 26, no. 2. pp. 263-285, 2000.

[8] Michailidou I., Roth M. and Lindemann U. "From Learning To Experiencing Principles of Engineering Design At the Tum," in 14th International Conference on Engineering and product design education, 2014, no. September.

[9] Sicart M. "Defining Game Mechanics," Game Stud. Int. J. Comput. game Res., vol. 8, no. 2, pp. $1-12,2008$.

[10] Kano N. "Attractive quality and must-be quality.," Hinshitsu Qual. J. Japanese Soc. Qual. Control, vol. 14., pp. 39-48, 1984.

[11] Mcmanus H.L. Product Development Value Stream Mapping (PDVSM) Manual, Lean Aeros., no. September. MIT, 2005.

[12] Mascitelli R. Mastering Lean Product Development. A practical Event-Driven Process for Maximizing SPeed Profits, and Quality. Technology Perspectives, 2011.

[13] Leach L.P. Critical Chain Project Management, Second edi. Artech House Publishers, 2004. 